\title{
Be careful when stopping short term dexamethasone therapy in SARS-CoV-2 infection: An experience
}

\author{
Monjuri Borkotokey ${ }^{1}$, Kaustuv Dutta ${ }^{2}$ \\ Author affiliation: \\ 1- Supercare Hospital, Sawlad, Demthring, Shillong-793021, Meghalaya, India \\ 2- Department of Anaesthesiology and Critical Care, NEIGRIHMS, Shillong-793018, Meghalaya, India \\ Correspondence: Dr. Monjuri Borkotokey; E- mail: dr.borkotokey@gmail.com; Phone: +91 8861050686 \\ Key words: Dexamethasone; Covid-19; Corticosteroid therapy
}

Citation: Borkotokey M, Dutta K. Be careful when stopping short term dexamethasone therapy in SARS-CoV-2 infection: An experience. Anaesth. pain intensive care 2020;24(6):698-699

Received: 29 October 2020-, Reviewed: 12 November 2020, Accepted: 15 November 2020

SARS-CoV-2 pandemic has taken a toll on the physical as well as mental health of the human race across the world. The potential lethality of the disease has led to the indiscriminate and desperate use of medications. The impact of the pandemic on the health care professionals has been unprecedented.

Corticosteroids, especially dexamethasone has been considered a key player in the treatment of severe SARS-CoV-2 infection. ${ }^{1}$ However, adequate caution must be taken during treatment with dexamethasone in Covid cases. I take this opportunity to share the story of my struggle with Covid and dexamethasone. I am a 35-year-old female with a past history of recurrent autoimmune pan uveitis which required treatment with oral prednisolone for over two and a half years. I started having body ache, on and off fever (not exceeding $100^{\circ} \mathrm{F}$ ) and sore throat shortly after my husband, who is a neurointensivist posted as the in-charge of Covid intensive care unit (ICU) was found to be Covid positive. Subsequently, I was also diagnosed as Covid positive. I opted for hospital isolation along with my husband and 4-year-old son, all of us being positive. My investigations on admission revealed Hb: 12.5 gm\%, Platelets: $190 \times 10^{3}$, WBC count: $6.2 \times 10^{3}$, Differential count: N66L26M5E3. Biochemistry investigations were as following: urea: $17 \mathrm{mg} / \mathrm{dL}$, creatinine: $0.6 \mathrm{mg} / \mathrm{dL}$, total bilirubin: $1.1 \mathrm{mg} / \mathrm{dL}$, AST: $86 \mathrm{U} / \mathrm{L}$, ALKP: $71 \mathrm{U} / \mathrm{L}$, Total protein: $6.9 \mathrm{~g} / \mathrm{dL}$, albumin: $4.8 \mathrm{~g} / \mathrm{dL}$, globulin: $2.10 \mathrm{~g} / \mathrm{dL}$. I was started on oral vitamin $\mathrm{C}$, zinc and azithromycin. Baseline CT scan chest revealed no abnormality. On the fourth day after admission, I developed dyspnea on exertion with oxygen saturation $94 \%$ to $96 \%$. I was immediately started on inj. low molecular weight heparin (LMWH), $40 \mathrm{mg}$ subcutaneously once daily. Considering my past history of prolonged steroid intake and autoimmune pan uveitis, I was started on inj. Dexamethasone 6 mg IV once daily. After the second dose of steroid, I felt considerable relief. After a course of 5 days, it was decided to discontinue both LMWH and dexamethasone as I was showing very good recovery. But the very next day after discontinuation of dexamethasone, I started having high grade fever of $102^{\circ} \mathrm{F}$ with incapacitating weakness. Extensive fever work-up was done and all blood and urine investigations were found to be within normal limits. IL-6 value was $20.67 \mathrm{pg} / \mathrm{mL}$ (Normal: $<7 \mathrm{pg} / \mathrm{mL}$ ). Urine was also sent for culture and sensitivity and was later found to have no pathogenic organisms. Since no particular cause of fever could be pin pointed, steroid withdrawal was suspected and dexamethasone was restarted. The fever resolved miraculously with a rapid improvement in weakness after the second dose of dexamethasone. Dexamethasone was continued for a total of ten days and was tapered for two days before stopping completely.

Corticosteroids have been widely used for the treatment of Covid-19. Dexamethasone, 6mg IV has been recommended to be used for upto10 days., ${ }^{1,2}$ Usually, Corticosteroid therapy do not need tapering when used for a short duration of 5 to 10 days. $^{3}$ However, the dose and duration of steroid required 
to suppress the Hypothalamic-Pituitary-Adrenal Axis (HPAA) is unpredictable. ${ }^{4}$ Hence, extreme caution should be taken while stopping the short term dexamethasone therapy abruptly. Also, whenever possible, tapering of the dexamethasone should always be preferred instead of abrupt termination of dexamethasone therapy irrespective of the duration and dose of treatment.

\section{Conflict of interest}

None declared by the authors.

\section{References}

1. Corticosteroids for COVID-19. World Health Organization. 2020 Sep 2. From WHO website. Available
https://www.who.int/publications/i/item/WHO-2019nCoV-Corticosteroids-2020.1. Accessed on 28.10.2020.

2. COVID-19 Treatment Guidelines Panel. Coronavirus Disease 2019 (COVID-19) Treatment Guidelines. National Institutes of Health. Available at: https://www.covid19treatmentguidelines.nih.gov/. Accessed on 28.10.2020.

3. Williams D. Clinical Pharmacology of Corticosteroids. Respir Care. 2018;63(6):655-670. [PubMed] DOI: 10.4187/respcare.06314

4. Schuetz $P$, Christ-Crain M, Schild U, Süess E, Facompre M, Baty $F$ et al. Effect of a 14-day course of systemic corticosteroids on the hypothalamicpituitary-adrenal-axis in patients with acute exacerbation of chronic obstructive pulmonary disease. BMC Pulm Med. 2008;8:1. .[PubMed] DOI: 10.1186/1471-2466-8-1 